\title{
Properties of AIN thin films deposited by means of magnetron sputtering for ISFET applications
}

\begin{abstract}
Piotr FireK*, MichaŁWaśkiewicz, BartŁomiej Stonio, Jan Szmidt
Institute of Microelectronics and Optoelectronics, Warsaw University of Technology, Koszykowa 75, 00-662 Warsaw, Poland

This work presents the investigations of AlN thin films deposited on Si substrates by means of magnetron sputtering. Nine different sputtering processes were performed. Based on obtained results, the tenth process was prepared and performed (for future ISFET structures manufacturing). Round aluminum ( $\mathrm{Al}$ ) electrodes were evaporated on the top of deposited layers. The MIS capacitor structures enabled a subsequent electrical characterization of the AlN films by means of current-voltage (I-V) and capacitance-voltage $(\mathrm{C}-\mathrm{V})$ measurements. Based on these results, the main parameters of investigated layers were obtained. Moreover, the paper describes the technology of fabrication and electrical characterization of ISFET transistors and possibility of their application as ion sensors.
\end{abstract}

Keywords: ISFET/MISFET technology; AlN; aluminum nitride; magnetron sputtering

(C) Wroclaw University of Technology.

\section{Introduction}

ISFET microsensors were widely used for $\mathrm{pH}$ measurements [1-3], analytical and biomedical applications and monitoring of ground water pollution. ISFET is a good candidate for the investigation of various materials for new sensitive membranes. Most often $\mathrm{Si}_{3} \mathrm{~N}_{4}$ is applied as an ISFET membrane material as well as $\mathrm{SiO}_{2}$, mainly because of its most polished deposition technology used in microelectronic industry. Amorphous $\mathrm{Si}_{3} \mathrm{~N}_{4}$ is suitable only in a limited way, because its gate is subjected to a high drift and cannot be used in aggressive media for a longer period of time. The $\mathrm{Si}_{3} \mathrm{~N}_{4}$-based devices show instability of the $\mathrm{pH}$ response caused by conversion of the nitride to a hydrated $\mathrm{SiO}_{2}$ or an oxynitride during the contact with an aqueous solution. In order to avoid disadvantages of $\mathrm{Si}_{3} \mathrm{~N}_{4}$, new dielectric materials, such as $\mathrm{Al}_{2} \mathrm{O}_{3}, \mathrm{Ta}_{2} \mathrm{O}_{5}$ and also novel high-k materials, like $\mathrm{ZrO}_{2}, \mathrm{HfO}_{2}, \mathrm{Y}_{2} \mathrm{O}_{3}$, and $\mathrm{Gd}_{2} \mathrm{O}_{3}, \mathrm{BaTiO}_{3}$, $\mathrm{Pr}_{2} \mathrm{O}_{3}$ and $\mathrm{PrTiO}_{3}$, were examined [1-3]. The reason for the introduction of alternative materials in silicon technology is primarily their high dielectric

*E-mail: P.Firek@elka.pw.edu.pl constant, which can improve the detection properties of the devices. At the same time there is a need for such coatings that have a high chemical resistance at high temperature, while maintaining the insulating properties that is high resistivity.

Several properties of the AlN films, such as, e.g. isomorphous crystallographic structure, high resistivity $\left(\sim 10^{13} \Omega \cdot \mathrm{cm}\right.$ ), high thermal stability (up to $2200{ }^{\circ} \mathrm{C}$ ), quite high value of dielectric constant ( $\sim 9)$ make them an excellent material for application in MIS/ISFET structures, as a gate dielectric [4-6]. Ion Sensitive Field Effect Transistor (ISFET) is a kind of Metal Insulator Semiconductor Field Effect Transistor (MISFET) in which the metal gate is replaced by an ion-sensitive membrane, an electrolyte solution and a reference electrode.

\section{Experimental}

\subsection{AIN deposition and characterization}

AlN films were deposited on p-type Si ( $\left(\begin{array}{lll}1 & 0 & 0\end{array}\right)$, $\rho=1$ to $10 \Omega \cdot \mathrm{cm}$ ) substrates using reactive magnetron sputtering method. All the processes were conducted with the use of Plasmalab 400, the device of Oxford Company. The experiment was 
designed by using an orthogonal matrix with four parameters: power density, pressure (of the mixture Ar and $\mathrm{N}_{2}$ ), $\mathrm{N}_{2} / \mathrm{Ar}$ flow ratio and deposition time and the elements of Taguchi's methods of optimization [7]. Table 1 presents the deposition process parameters and their given values. All the experiments were implemented with the target-substrate distance of $100 \mathrm{~mm}$ and 8 inch target diameter. The process parameters are summarized in Table 2.

Round, aluminum (Al) electrodes were vacuum-evaporated on the top of the deposited layers.

Thus, metal-insulator-semiconductor (MIS) structures were created which enabled the calculation of various parameters of the deposited AIN films based on their electrical characterization (current-voltage (I-V) and capacitance-voltage (C-V) measurements). Current-voltage characteristics were obtained using Keithley SMU 238, whereas high-frequency $(1 \mathrm{MHz}) \mathrm{C}-\mathrm{V}$ measurements were performed using HP 4061A test station.

Following the analysis of the properties of deposited films, optimum process parameters have been selected in view of obtaining the lowest possible flat-band voltage, while maintaining reasonable values of dielectric constant. This should allow obtaining MISFET structures with low threshold voltage.

On this basis, a new process was developed with the parameters given in Table 3.

After preparation of MIS capacitor structures with dielectric films deposited in magnetron sputtering process described in Table 3, the currentvoltage (I-V) and capacitance-voltage $(\mathrm{C}-\mathrm{V})$ characteristics were measured. Then the wafers were annealed in accordance with the parameters in Table 4 and the electrical characteristics were measured again.

In addition to electrical measurements, the analyzes of selected samples were also performed using atomic force microscopy (AFM). Moreover, the optical parameters of the obtained layers were studied with a spectroscopic ellipsometer (HORIBA JOBIN YVON UVISEL).

\subsection{MIS/ISFET fabrication and charac- terization}

The first step of fabrication process of Metal Insulator Semiconductor/Ion Sensitive Field Effect Transistor (MI/ISFET) structures was thermal oxidation in order to obtain a field oxide of about $440 \mathrm{~nm}$. A p-type silicon (1 00 ) oriented substrate with resistivity of 1 to $10 \Omega \cdot \mathrm{cm}$ was used. After the first photolithography, drain and source areas for doping were opened and doped with phosphorous. In the next step, $20 \mathrm{~nm}$ thick $\mathrm{SiO}_{2}$ film was produced by thermal oxidation and then aluminum nitride film was deposited by means of magnetron sputtering method. Another photolithography allowed the preparation of a photoresist mask for wet etching process. The AlN layers were etched in a solution of phosphoric acid $\left(\mathrm{H}_{3} \mathrm{PO}_{4}: \mathrm{CH}_{3} \mathrm{COOH}: \mathrm{H}_{2} \mathrm{O}: \mathrm{HNO}_{3}(31: 6: 2: 1)\right)$ in a temperature of $60{ }^{\circ} \mathrm{C}$. At the last step, contacts for metallization were opened and aluminum was evaporated.

Photolithography masks used in the processes allowed manufacturing of two types of transistors on a single wafer: ISFET structures with ion exposed gate and MISFET structures with aluminum gate electrode.

The current-voltage (I-V) characteristics of $\mathrm{SiO}_{2} / \mathrm{AlN}$ containing MISFET structures were measured with Keithley SMU 236/237/238 measurement set.

\section{Results}

\subsection{Morphology and structural composi- tion of the AIN films}

Surface morphology of the obtained layers was studied by atomic force microscopy (AFM): the images are shown in Fig. $1-3$. The films show a uniform thickness and are smooth with the roughness parameters collected in Table 5.

\subsection{Optical properties of deposited films}

Results of investigations of optical properties have been collected in Table 6 . 
Table 1. Orthogonal table of deposition.

\begin{tabular}{cccccc}
\hline $\begin{array}{c}\text { Parameter } \\
\text { value }\end{array}$ & $\begin{array}{c}\text { Power density } \\
{\left[\mathrm{W} / \mathrm{cm}^{2}\right]}\end{array}$ & $\begin{array}{c}\text { Power } \\
{[\mathrm{W}]}\end{array}$ & $\begin{array}{c}\text { Pressure } \\
{[\mathrm{Pa}]}\end{array}$ & $\begin{array}{c}\text { Ratio } \mathrm{N}_{2} / \mathrm{Ar} \\
{[\mathrm{sccm} / \mathrm{sccm}]}\end{array}$ & $\begin{array}{c}\text { Time } \\
{[\mathrm{min}]}\end{array}$ \\
\hline \hline 1 & 1.54 & $(500)$ & 0.4 & 1 & 3 \\
2 & 2.78 & $(900)$ & 0.8 & 1.5 & 6 \\
3 & 4.00 & $(1300)$ & 1.33 & 2.33 & 9 \\
\hline
\end{tabular}

Table 2. Magnetron sputtering process parameters.

\begin{tabular}{cccccc}
\hline Run & $\begin{array}{c}\text { Power density } \\
{\left[\mathrm{W} / \mathrm{cm}^{2}\right]}\end{array}$ & $\begin{array}{c}\text { Power } \\
{[\mathrm{W}]}\end{array}$ & $\begin{array}{c}\text { Pressure } \\
{[\mathrm{Pa}]}\end{array}$ & $\begin{array}{c}\text { Ratio } \mathrm{N}_{2} / \mathrm{Ar} \\
{[\mathrm{sccm} / \mathrm{sccm}]}\end{array}$ & $\begin{array}{c}\text { Time } \\
{[\mathrm{min}]}\end{array}$ \\
\hline \hline 1 & 1.54 & $(500)$ & 0.4 & 1 & 3 \\
2 & 1.54 & $(500)$ & 0.8 & 1.5 & 6 \\
3 & 1.54 & $(500)$ & 1.33 & 2.33 & 9 \\
4 & 2.78 & $(900)$ & 0.4 & 1.5 & 9 \\
5 & 2.78 & $(900)$ & 0.8 & 2.33 & 3 \\
6 & 2.78 & $(900)$ & 1.33 & 1 & 6 \\
7 & 4.00 & $(1300)$ & 0.4 & 2.33 & 6 \\
8 & 4.00 & $(1300)$ & 0.8 & 1 & 9 \\
9 & 4.00 & $(1300)$ & 1.33 & 1.5 & 3 \\
\hline
\end{tabular}

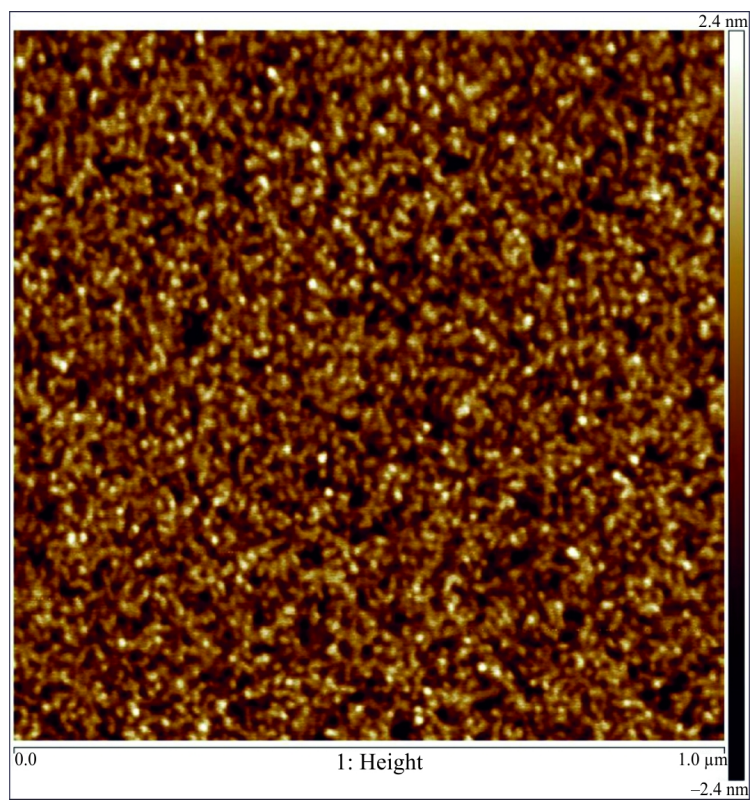

Fig. 1. AFM image of sample 3.

\subsection{Electrical properties of the layers}

Results of C-V measurements of produced capacitors are shown in Fig. 4 and Fig. 5. It can be

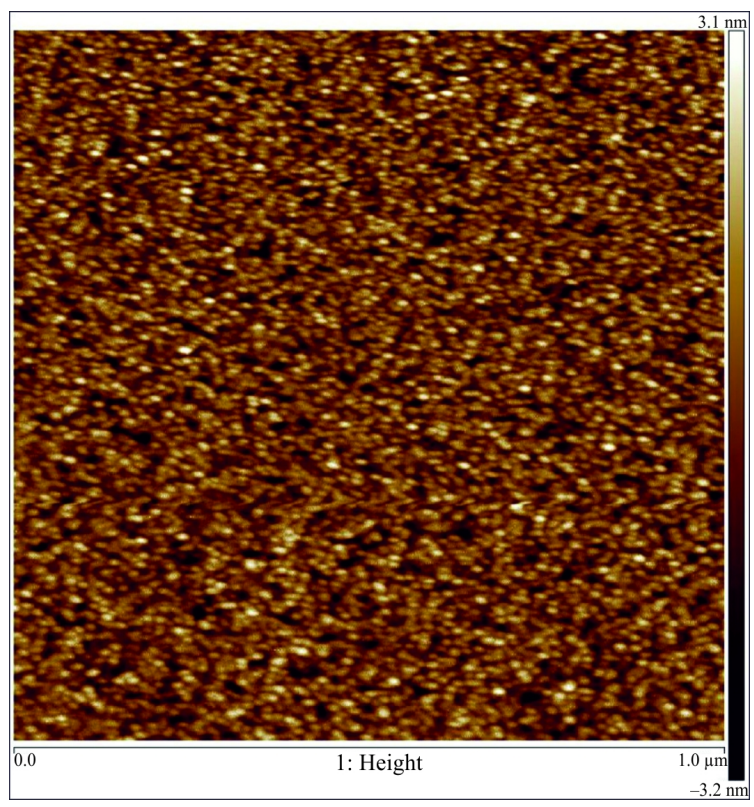

Fig. 2. AFM image of sample 6.

noticed that the measurement results for different capacitors manufactured in the same process are repeatable. The parameters calculated from $\mathrm{C}-\mathrm{V}$ characteristics are collected in Table 7. In Fig. 6 
Table 3. Magnetron sputtering process parameters chosen for ISFET fabrication.

\begin{tabular}{cccccc}
\hline Run & $\begin{array}{c}\text { Power density } \\
{\left[\mathrm{W} / \mathrm{cm}^{2}\right]}\end{array}$ & $\begin{array}{c}\text { Power } \\
{[\mathrm{W}]}\end{array}$ & $\begin{array}{c}\text { Pressure } \\
{[\mathrm{Pa}]}\end{array}$ & $\begin{array}{c}\text { Ratio } \mathrm{N}_{2} / \mathrm{Ar} \\
{[\mathrm{sccm} / \mathrm{sccm}]}\end{array}$ & $\begin{array}{c}\text { Time } \\
{[\mathrm{min}]}\end{array}$ \\
\hline \hline 10 & 2.78 & 900 & 0.8 & 1.5 & 6 \\
\hline
\end{tabular}

Table 4. Parameters of MIS capacitors annealing.

\begin{tabular}{ccc}
\hline Time & 30 & {$[\mathrm{~min}]$} \\
Temperature & 300 & {$\left[{ }^{\circ} \mathrm{C}\right]$} \\
Gas & $\mathrm{N}_{2}$ & \\
\hline
\end{tabular}

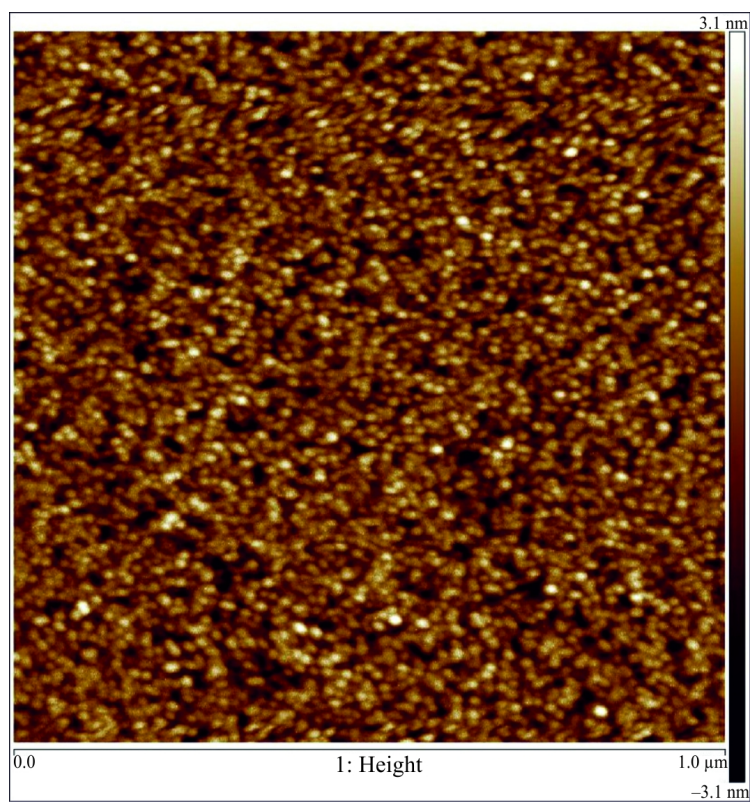

Fig. 3. AFM image of sample 9.

the influence of the deposition process parameters on electrical parameters is presented.

Electrical characteristics (I-V) of fabricated MIS structures are shown in Fig. 7 and Fig. 8. The curves are repeatable and show good insulating properties.

\subsection{Electrical properties of ISFET tran- sistor}

The obtained transfer and output characteristics are presented in Fig. 9 and Fig. 10.

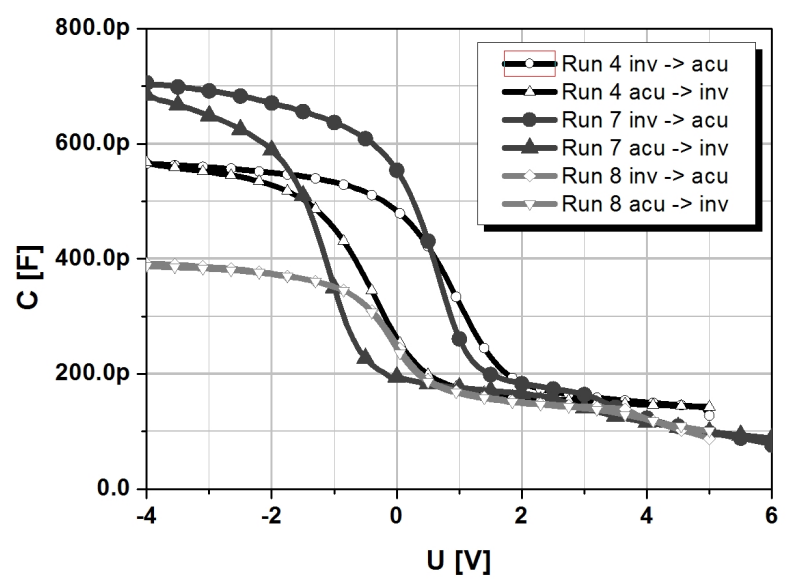

Fig. 4. Comparison of $\mathrm{C}-\mathrm{V}$ characteristics.

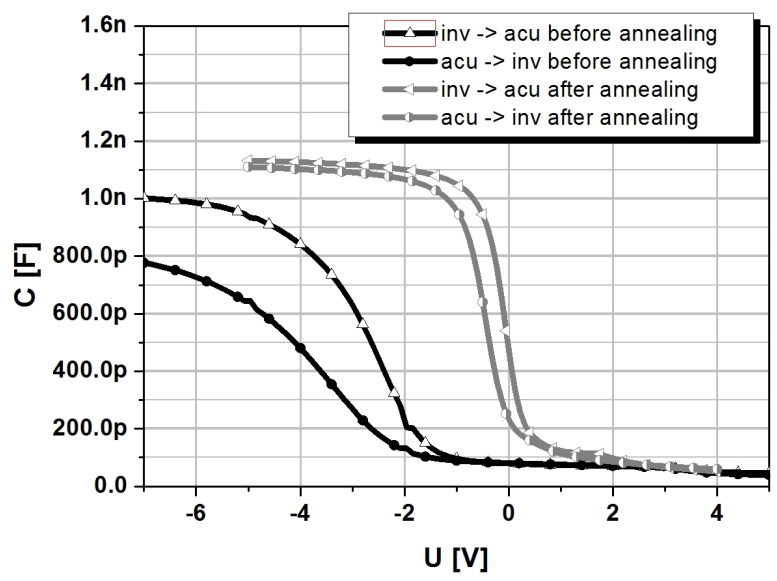

Fig. 5. C-V characteristics of capacitors from run 10.

\section{Discussion}

The influence of the input parameters of power, pressure and $\mathrm{Ar} / \mathrm{N}_{2}$ ratio on electrical parameters is presented in Fig. 6. The analysis of such relations allows us to select the most favorable deposition parameters for high permittivity, low flatband voltage level (which subsequently results in low values of threshold voltage), charge trap density and effective charge, as well. As it can be seen on the presented graphs (Fig. 6), the parameters 
Table 5. AlN films parameters obtained from AFM.

\begin{tabular}{cccc}
\hline Run & $\begin{array}{c}\text { RMS roughness } \\
\left(\mathrm{R}_{\mathrm{q}}\right)\end{array}$ & $\begin{array}{c}\text { Average roughness } \\
{[\mathrm{nm}]}\end{array}$ & $\begin{array}{c}\text { Maximum peak height } \\
\left(\mathrm{R}_{\mathrm{a}}\right)\end{array}$ \\
\hline \hline 3 & 0.705 & 0.565 & {$[\mathrm{~nm}]$} \\
6 & 0.906 & 0.722 & 5.92 \\
9 & 0.882 & 0.703 & 7.64 \\
\hline
\end{tabular}

Table 6. Optical properties of deposited AlN films.

\begin{tabular}{cccc}
\hline Run & $\begin{array}{c}\text { Thickness } \\
{[\mathrm{nm}]}\end{array}$ & $\begin{array}{c}\text { Deposition rate } \\
{[\mathrm{nm} / \mathrm{min}]}\end{array}$ & $\begin{array}{c}\text { Refractive index } \\
(\lambda=632 \mathrm{~nm})\end{array}$ \\
\hline \hline 1 & 52.3 & 17.43 & 2.01 \\
2 & 75.7 & 12.62 & 1.86 \\
3 & 50.0 & 5.56 & 1.93 \\
4 & 137.2 & 15.22 & 2.04 \\
5 & 40.4 & 13.47 & 1.96 \\
6 & 92.8 & 15.47 & 1.89 \\
7 & 124.1 & 20.68 & 2.07 \\
8 & 192.5 & 21.39 & 1.96 \\
9 & 59.0 & 19.67 & 1.65 \\
10 (before annealing) & 59.0 & 9.83 & 1.94 \\
\hline
\end{tabular}

Table 7. Electrical properties of fabricated MIS capacitors.

\begin{tabular}{ccccccc}
\hline Run & $\begin{array}{c}\mathrm{C}_{\max } \\
{[\mathrm{nF}]}\end{array}$ & $\begin{array}{c}\mathrm{C}_{\min } \\
{[\mathrm{nF}]}\end{array}$ & Permittivity & $\begin{array}{c}\text { Flat-band voltage } \\
{[\mathrm{V}]}\end{array}$ & $\begin{array}{c}\text { Charge trap density } \\
{\left[\mathrm{cm}^{-2} \cdot \mathrm{eV}^{-1}\right]}\end{array}$ & $\begin{array}{c}\text { Effective charge } \\
{\left[\mathrm{C} / \mathrm{cm}^{3}\right]}\end{array}$ \\
\hline \hline 1 & 1.18 & 0.090 & 8.5 & -7.4 & $3.6 \times 10^{12}$ & $7.7 \times 10^{-7}$ \\
2 & 0.73 & 0.076 & 5.25 & -1.7 & $3.2 \times 10^{11}$ & $1.5 \times 10^{-7}$ \\
3 & 1.22 & 0.092 & 8.7 & -2.9 & $7.4 \times 10^{11}$ & $2.1 \times 10^{-7}$ \\
4 & 0.58 & 0.150 & 4.1 & -1.6 & $8.9 \times 10^{11}$ & $4.2 \times 10^{-8}$ \\
5 & 0.98 & 0.047 & 7.1 & -2.6 & $7.1 \times 10^{11}$ & $1.9 \times 10^{-7}$ \\
6 & 0.63 & 0.096 & 4.5 & -2.2 & $3.3 \times 10^{11}$ & $9.7 \times 10^{-8}$ \\
7 & 0.71 & 0.120 & 5.1 & -0.2 & $8.0 \times 10^{12}$ & $8.1 \times 10^{-8}$ \\
8 & 0.41 & 0.120 & 2.9 & -1.4 & $3.4 \times 10^{12}$ & $2.5 \times 10^{-8}$ \\
9 & 1.23 & 0.110 & 8.8 & -2.0 & $8.9 \times 10^{12}$ & $7.7 \times 10^{-8}$ \\
10 (annealed) & 1.07 & 0.050 & 9.8 & -0.95 & $3.5 \times 10^{12}$ & $8.6 \times 10^{-8}$ \\
\hline
\end{tabular}

selection is always a compromise. The selected parameters of the AlN deposition process were used in the experiment marked as 10 . The manufactured capacitors are characterized by a flat-band voltage of near $-1 \mathrm{~V}$ and insignificant hysteresis. This allows for treating the obtained results as very good and promising for the application in the gate dielectric films for MISFET devices due to the possibility of achieving a relatively low threshold voltage. The refractive index (about 1.9) and optical band gap (about $4.6 \mathrm{eV}$ ) suggest that the deposited films possess dominant AlN properties even though they are not crystalline (parameters for crystalline films: band gap: $6.2 \mathrm{eV}$, refractive index: 1.9 to 2.2). Dielectric constant of the stack $\mathrm{SiO}_{2} / \mathrm{AlN}$ deposited in the run 10 was 9.8 (after 

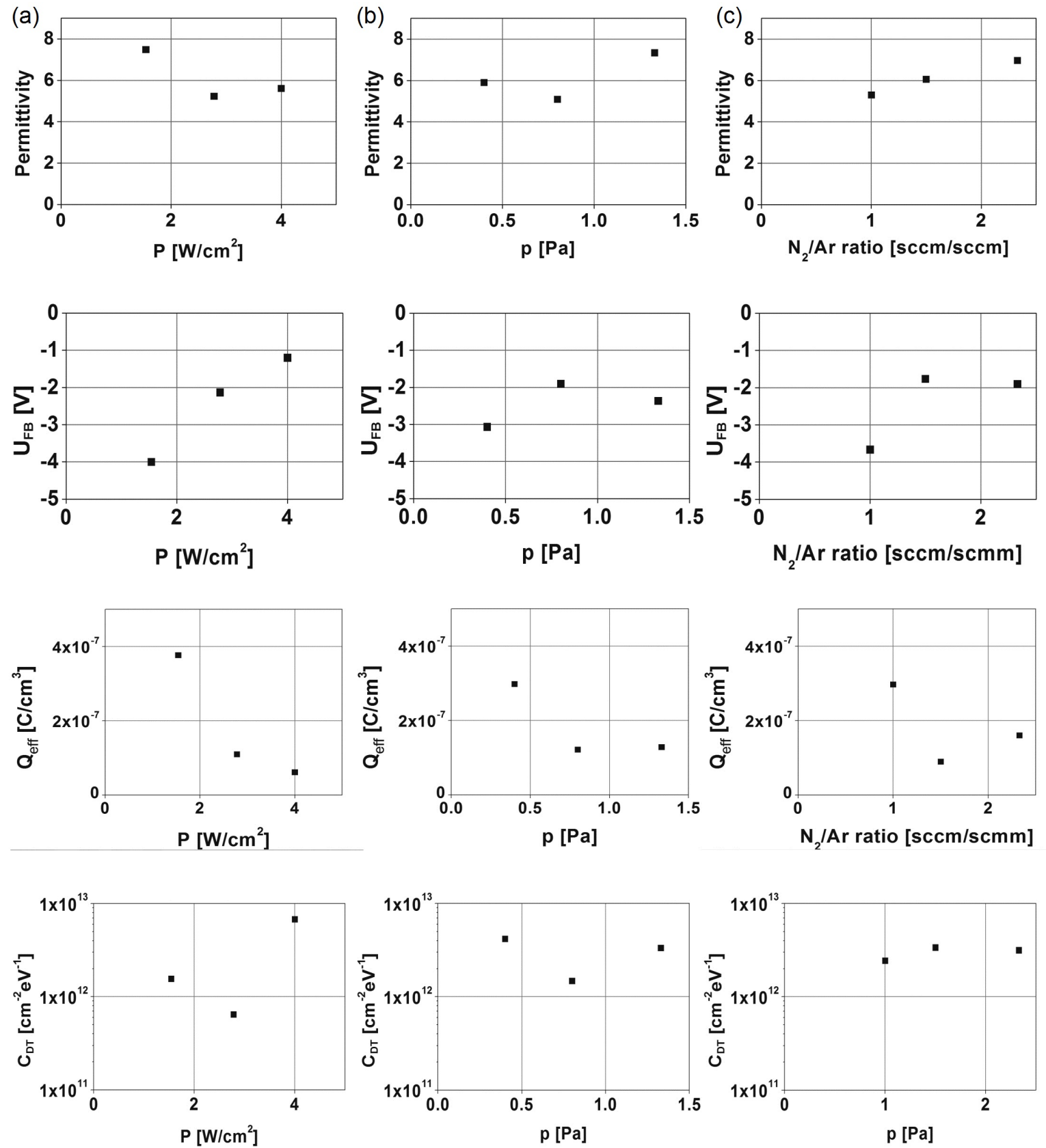

Fig. 6. Influence of: (a) power, (b) pressure, (c) $\mathrm{N}_{2} / \mathrm{Ar}$ flow ratio on the selected electrical parameters.

annealing), which is a high value in comparison to $\mathrm{SiO}_{2}$ (3.9), $\mathrm{Si}_{3} \mathrm{O}_{\mathrm{x}} \mathrm{N}_{\mathrm{y}}$ (5.6 [8]), $\mathrm{BN}$ (5.5 [9]), $\mathrm{Al}_{2} \mathrm{O}_{3}$ (6.5 [10]) or $\mathrm{Gd}_{2} \mathrm{O}_{3}$ (8 [11]). Yet, it should be taken into account that it usually depends on the layer production method. Effective charge $\left(\mathrm{Q}_{\mathrm{eff}}\right)$ and surface state density are on the satisfactory level. Moreover, $\mathrm{Q}_{\text {eff value shows that the obtained }}$ layer is very promising from transistors point of view (low charge in dielectric region indicates low values of threshold voltage).

In case of the obtained transistor (MISFET) structures, the threshold voltage was approximately $3 \mathrm{~V}$. Threshold voltage $\left(\mathrm{U}_{\mathrm{T}}\right)$ is one of the most important parameters of a transistor and represents the voltage value when MISFET channel is turned on. The obtained results are adequate for 


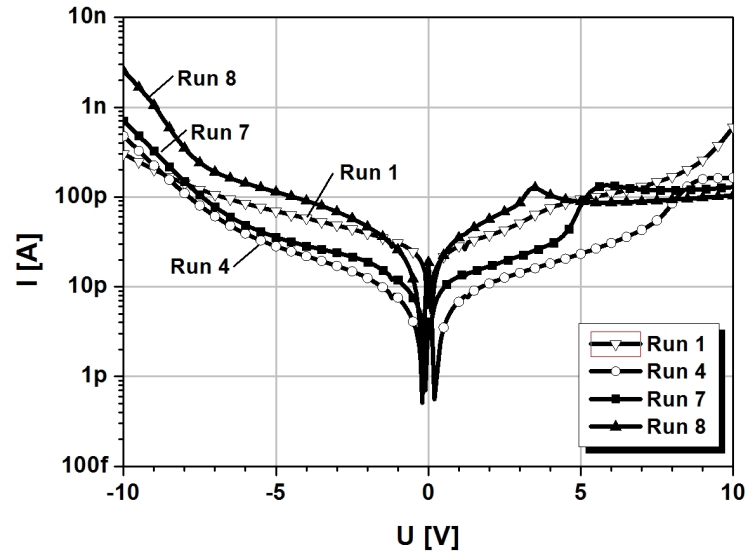

Fig. 7. Comparison of $I-V$ characteristics.

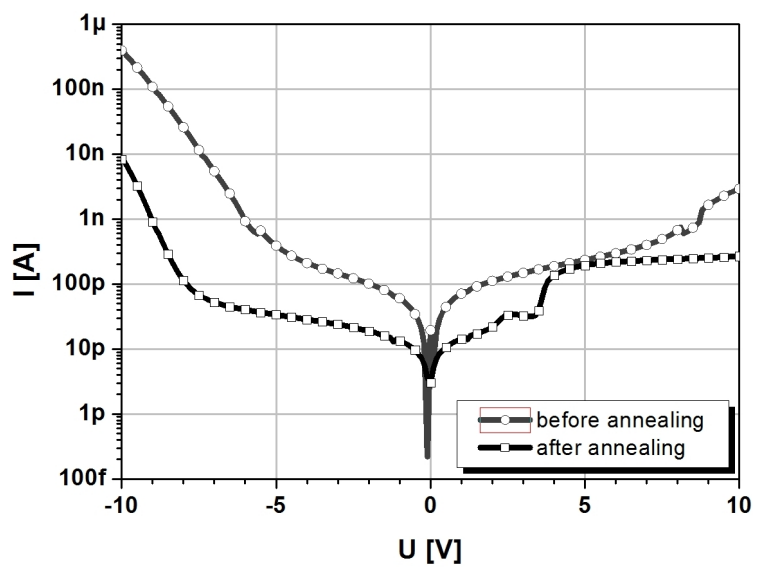

Fig. 8. I-V characteristics of capacitors from run 10.

MISFETs with the gate stack made from other materials, e.g. $\mathrm{BaTiO}_{3}$ [12], where the obtained values of the threshold voltage were several times higher $(6 \mathrm{~V})$. The very promising permittivity and treshold voltage values make AlN a quite interesting material from the IS (Ion Sensitive) FET structures point of view.

\section{Conclusions}

The obtained AlN films show good adhesion to $\mathrm{SiO}_{2}$ layers and silicon substrates. They have relatively high dielectric constant. Quite low values of the threshold voltage show that two interfaces, $\mathrm{Si}-\mathrm{SiO}_{2}$ and $\mathrm{SiO}_{2}-\mathrm{AlN}$, have good properties, i.e. low level of traps density and surface charge. AlN layers exhibit several very interesting

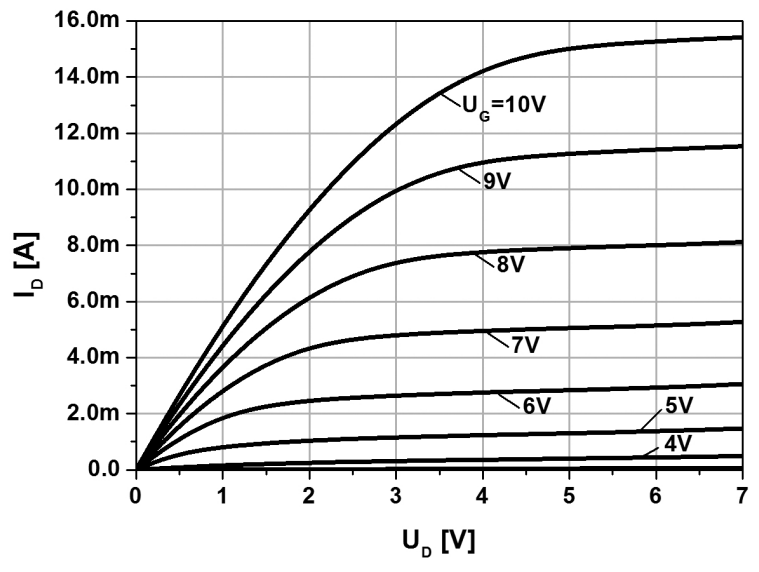

Fig. 9. Output characteristics of MISFET transistor.

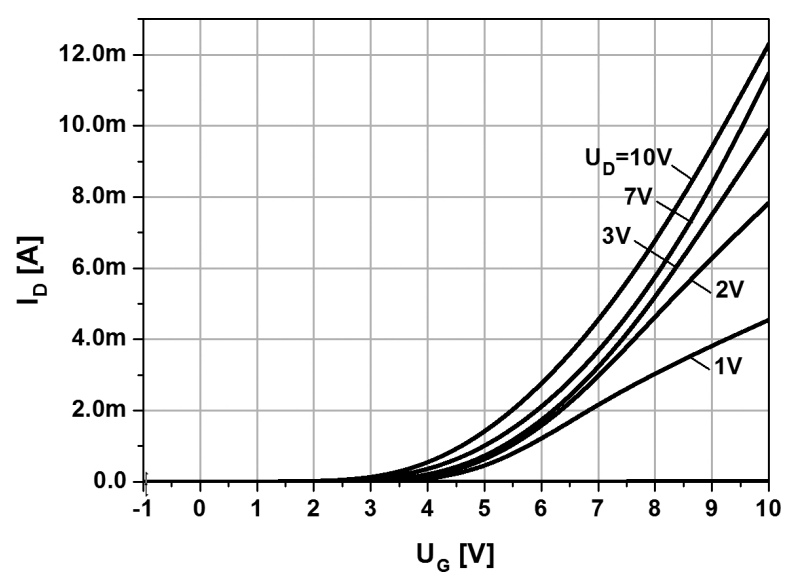

Fig. 10. Transient characteristics of MISFET transistor.

electronic properties, which make this material promising from sensor point of view, especially for ISFET structures.

\section{Acknowledgements}

This work was supported by The National Science Centre (Grant No. N N515 498140, UMO-2011/01/D/ST7/00640). Also, special thanks to Małgorzata Kalisz for images obtained by atomic force microscopy.

\section{References}

[1] Poghossian A., Berndsen L., Schöning M.J., Sensor. Actuat. B-Chem., 95 (2003), 384.

[2] Tung M.P., Sensor. Actuat. B-Chem., 133 (2008), 97.

[3] Bergveld P., Sensor. Actuat. B-Chem., 88 (2003), 1.

[4] Zhenghua A., Chuanling M., Zhengkui X., Paul K.C., Chenglu L., Surf. Coat. Tech., 196 (1 3) (2005), 130. 
[5] Mileham J.R., Pearton S.J., Abernathy C.R., MACKenzIE J.D., Shul R.J., Kilcoyne S.P., J. Vac. Sci. Technol. A, 14 (3) (1996), 836.

[6] Adam T., Kolodzey J., Swann C.P., Tsao M.W., RABOLT J.F., Appl. Surf. Sci., 175 - 176 (2001), 428.

[7] Taguchi G., Konishi S., Orthogonal Arrays and Linear Graphs, ASI Press, Dearborn, 1987.

[8] Mroczyński R., Beck R.B., J. Vac. Sci. Technol. B, 27 (1) (2009), 494.

[9] Firek P., Werbowy A., Konarski P., Szmidt J., OLSZYNA O., Influence of the temperature on electronic properties of carbon-rich $B N$ films obtained from $\left(\mathrm{C}_{2} \mathrm{H}_{5}\right)_{3} \mathrm{~B}$ by means of Reactive Pulse Plasma method, in: LeE J., Novikov N., TurKevich V. (Eds.), Innovative Superhard Materials and Sustainable Coating for Advanced Manufacturing, NATO Science Series, Vol. 200, Kluwer, 2005.
[10] Firek P., SzMidt J., Nowakowska-LangieR K. Zdunek K., Plasma Process. Polym., 6 (2009), S840.

[11] GRYGlewicz J., FIREK P., JASIŃSKI J., Mroczyński R., SZMidT J., Proc. SPIE, 8902 (2013), 89022M-1.

[12] FIREK P., SZMIDT J., Microelectron. Reliab., 51 (2011), 1187.

Received 2014-01-13

Accepted 2015-06-16 